\title{
Ionization dynamics of iron plumes generated by laser ablation versus a laser-ablation-assisted-plasma discharge ion source
}

\author{
J. S. Lash, R. M. Gilgenbach, ${ }^{\text {a) }}$ and H. L. Spindler \\ Department of Nuclear Engineering and Radiological Sciences, Intense Energy Beam Interaction \\ Laboratory, The University of Michigan, Ann Arbor, Michigan 48109-2104
}

(Received 24 August 1995; accepted for publication 17 November 1995)

\begin{abstract}
The ionization dynamics (iron ion and neutral atom absolute line densities) produced in the $\mathrm{KrF}$ excimer laser ablation of iron and a laser-ablation-assisted plasma discharge (LAAPD) ion source have been characterized by a new dye-laser-based resonant ultraviolet interferometry diagnostic. The ablated material is produced by focusing a $\mathrm{KrF}$ excimer laser $(248 \mathrm{~nm},<1 \mathrm{~J}, 40 \mathrm{~ns}$ ) onto a solid iron target. The LAAPD ion source configuration employs an annular electrode in front of the grounded target. Simultaneous to the excimer laser striking the target, a three-element, inductorcapacitor, pulse-forming network is discharged across the electrode-target gap. Peak discharge parameters of $3600 \mathrm{~V}$ and $680 \mathrm{~A}$ yield a peak discharge power of $1.3 \mathrm{MW}$ through the laser ablation plume. Iron neutral atom line densities are measured by tuning the dye laser near the $271.903 \mathrm{~nm}$ $\left(a^{5} D-y{ }^{5} P^{0}\right)$ ground-state and $273.358 \mathrm{~nm}\left(a^{5} F-w^{5} D^{0}\right)$ excited-state transitions while iron singly ionized line densities are measured using the $263.105 \mathrm{~nm}\left(a^{6} D-z^{6} D^{0}\right)$ and $273.955 \mathrm{~nm}$ $\left(a^{4} D-z{ }^{4} D^{0}\right)$ excited-state transitions. The line density, expansion velocity, temperature, and number of each species have been characterized as a function of time for laser ablation and the LAAPD. Data analysis assuming a Boltzmann distribution yields the ionization ratio $\left(n_{i} / n_{n}\right)$ and indicates that the laser ablation plume is substantially ionized. With application of the discharge, neutral iron atoms are depleted from the plume, while iron ions are created, resulting in a factor of $\sim 5$ increase in the plume ionization ratio. Species temperatures range from 0.5 to $1.0 \mathrm{eV}$ while ion line densities in excess of $1 \times 10^{15} \mathrm{~cm}^{-2}$ have been measured, implying peak ion densities of $\sim 1 \times 10^{15} \mathrm{~cm}^{-3}$. () 1996 American Institute of Physics. [S0021-8979(96)00205-7]
\end{abstract}

\section{INTRODUCTION}

Application of laser ablation to thin-film deposition requires a detailed knowledge of the population densities and temperatures of ions and neutral atoms in the ablated plume. The laser-ablation-assisted plasma discharge (LAAPD) is of interest as it provides a means of changing the ionization fraction and temperature of the ablation plume. This control over the plume ion population may be used in deposition studies where the importance of moderate energy ions has been demonstrated. ${ }^{1}$ Previous research investigating the ionization in laser ablation plumes has been performed using laser-induced fluorescence $(\mathrm{LIF})^{2}$ and direct particle detection. ${ }^{3-5}$ The need for the measurement of speciesspecific plasma densities (both relative and absolute) in laserablation plumes and other plasma sources, has given rise to research utilizing a number of diagnostics including laserinduced fluorescence LIF, ${ }^{6}$ optical absorption, ${ }^{6,7}$ emission spectroscopy, ${ }^{8}$ and hook spectroscopy. ${ }^{9}$ Various interferometric methods for measuring both total particle densities and species-specific plasma densities have also been researched, including Michelson interferometry ${ }^{10}$ and resonant holographic interferometry (RHI). ${ }^{11-14}$ Interferometry has also been used to measure neutral particle line densities in gas discharges ${ }^{15}$ and electron densities in laser-triggered switches. ${ }^{16}$ Interferometric methods have the advantage over LIF and absorption spectroscopy in that interferometry is an absolute diagnostic and is insensitive to the magnitude of the

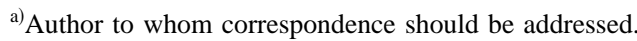

probing laser beam (detected light). This is especially important in laser-ablative deposition experiments when chamber windows may become coated, reducing optical transmission.

In this article, we present an original investigation of the two-dimensional, temporal evolution of the ionization dynamics in laser ablation of iron and an iron (LAAPD) ion source ${ }^{17}$ using a new dye-laser-based resonant ultraviolet interferometry (RUVI) diagnostic. The Mach-Zehnder interferometer is advantageous in that it only uses one pulse of the dye laser beam as opposed to the two pulses required for RHI. This allows the RUVI diagnostic to be applied in realtime studies or monitoring of species-specific line densities. The diagnostic utilizes the orders of magnitude increase in index of refraction near an atomic or ionic resonance transition. Hence, specific atoms or ions in various energy states can be investigated by tuning to an appropriate transition. In this article, two transitions for iron ions (Fe II) and neutral atoms (Fe I) are used, which allow measurement of the absolute line density for two separate populations in each species. For these populations, the absolute line density, expansion velocity, temperature, and number of each species are compared with laser ablation only and the LAAPD to characterize the evolution of the plume ionization as well as the dynamics of each species.

\section{EXPERIMENTAL CONFIGURATION}

Figure 1 shows a simplified experimental laser ablation and LAAPD ion source configuration on the optical table 
Excimer Laser

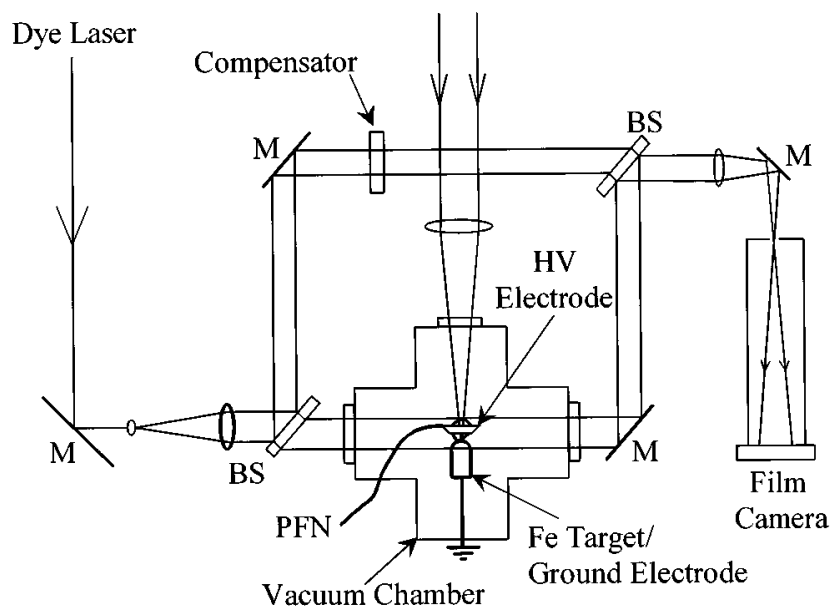

FIG. 1. Simplified experimental configuration of Mach-Zehnder interferometer and laser beam optics with M and BS denoting mirror and beam splitter, repectively.

used for the RUVI diagnostic. Not shown in Fig. 1 are the charging supply and associated electronics for the LAAPD (given in Refs. 17 and 18). Laser ablation plumes (source material for the LAAPD) are produced by focusing a $\mathrm{KrF}$ excimer laser ( $248 \mathrm{~nm},<1 \mathrm{~J}, 40 \mathrm{~ns})$ onto a $99.99 \%$ pure, solid iron target. Typical fluences are approximately $7 \mathrm{~J} / \mathrm{cm}^{2}$ with a laser focal spot of $0.05 \mathrm{~cm}^{2}$. The incident $\mathrm{KrF}$ laser energy is monitored by periodically measuring the laser output energy directly and converting to an at-target energy by the known attenuation of the optical path. The $\mathrm{KrF}$ excimer laser beam is focused onto the target with an $f=25 \mathrm{~cm}$, UVgrade, fused silica lens before passing into the chamber through an UV-grade fused silica window. For timing purposes, a silicon photodiode is used to observe the laser pulse. Evacuation for these experiments is provided by a mechanically backed turbomolecular vacuum pump system yielding working pressures of $6 \times 10^{-7}-1 \times 10^{-6}$ Torr as measured by an ionization gauge.

The LAAPD ion source configuration consists of an annular copper electrode placed approximately $7 \mathrm{~mm}$ in front of the grounded target. The annular electrode shape was chosen to allow the excimer laser to strike the target perpendicular to its surface and also result in a uniform discharge about the cylindrical target. The LAAPD power is provided by a three-element inductor-capacitor pulse forming network (PFN). The PFN is discharged by an air-filled spark gap switch. With a matched load of $2 \Omega$, the PFN provides a flat voltage pulse $2 \mu$ s in length. However a $10 \Omega$ viewing resistor was placed in parallel with the electrode-target gap to allow determination of the voltage across the gap. The resistance value was chosen to give the fastest rise in current and voltage in order to couple as much power into the plume before the plume had significantly expanded beyond the electrode-target gap. The PFN is charged to $7500 \mathrm{~V}$ yielding a peak discharge voltage of $3600 \mathrm{~V}$ and a peak discharge current of $680 \mathrm{~A}$, combining to give a peak instantaneous power of 1.3 MW through the laser ablation plume. For each

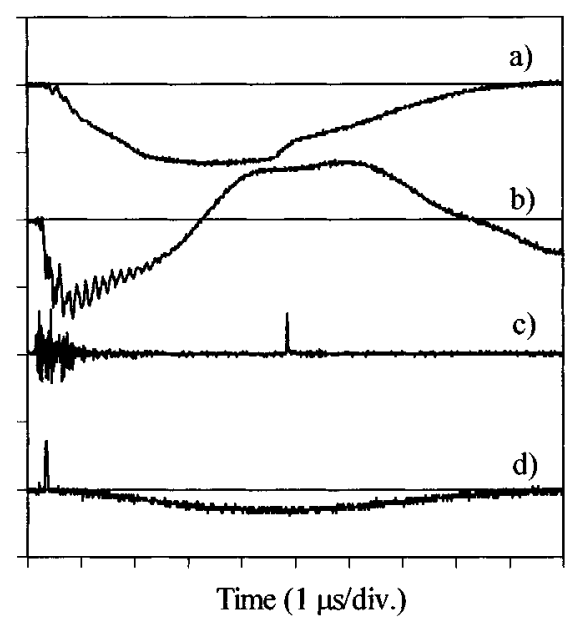

FIG. 2. Typical LAAPD wave forms and signals: (a) discharge current from ring electrode to target $(600 \mathrm{~A} / \mathrm{div})$, (b) discharge voltage at ring electrode with respect to grounded target $(3 \mathrm{kV} / \mathrm{div})$, (c) PIN diode signal of dye-laser pulse ( $1 \mathrm{~V} / \mathrm{div})$, and (d) silicon photodiode signal of $\mathrm{KrF}$ excimer laser pulse (2 V/div).

shot, current (and voltage across the viewing resistor) was measured inductively with Pearson current transformers which have a fast rise time ( $\sim 20 \mathrm{~ns})$ and voltage to current ratios of 1 or 10 V/A. Figure 2 shows typical current and voltage wave forms from the discharge as well as the photodiode signals of the excimer and dye laser pulses.

A XeCl excimer pumped dye laser ( $\sim 1 \mathrm{~mJ}, 20 \mathrm{~ns})$ with a second-harmonic generation crystal installed is used to probe the plume with a wavelength tunable between 260 and $290 \mathrm{~nm}$. The dye laser beam is enlarged and collimated by a telescope before passing to the interferometer. The beam splitters consist of uncoated UV-grade fused silica interferometry flats with a 3 arcmin wedge between the faces. With the surfaces of the beam splitters nonparallel, the first and second surface reflections can be spatially separated, rendering a second-surface antireflection coating unnecessary. Beam turning is accomplished using UV-enhanced aluminum-coated mirrors. As the object beam must pass through the 3/4-in.-thick chamber windows (introducing phase shift), an additional optical flat is placed in the reference beam to compensate for the phase shift in the object beam. Finally both beams are recombined, but with a slight angular separation to produce interference fringes for reference. Straight reference fringes are desired in the absence of the plume, but the high sensitivity of the interferometer combined with optical aberrations, results in slightly curved reference fringes. In this case, a template of the reference fringes is used for fringe-shift determination from which equiline-density contours are obtained by connecting points of equal fringe shift with respect to the reference fringes. Recording of the interferogram is accomplished using a pinhole camera and Polaroid 667 (3000 ASA) instant film. The theory of resonant interferogram interpretation relating 


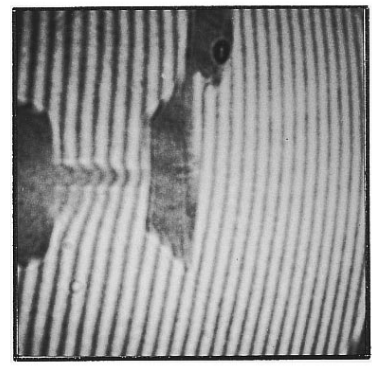

a)

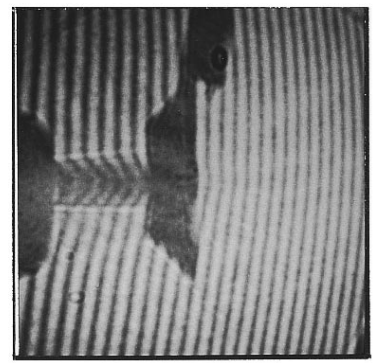

c)

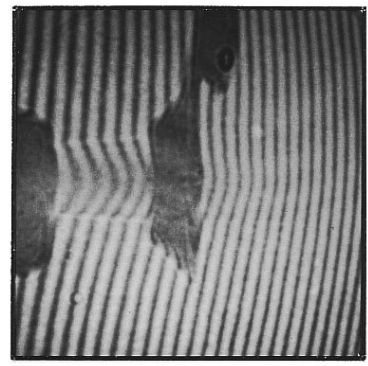

e)

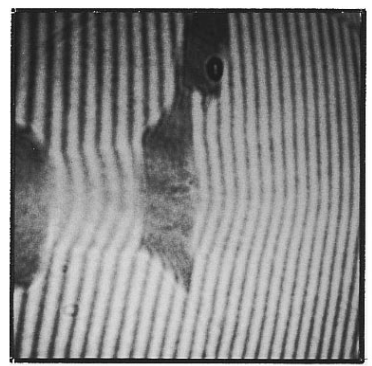

g)

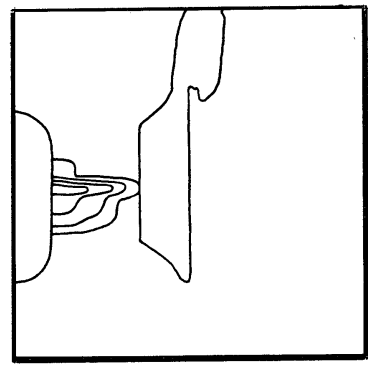

b)

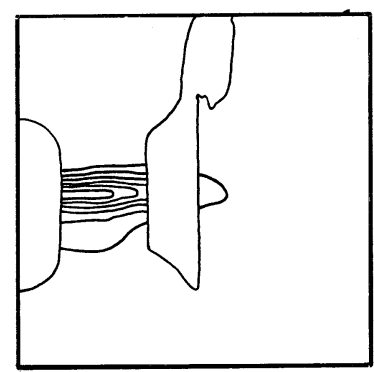

d)
$1 \mathrm{~cm}$

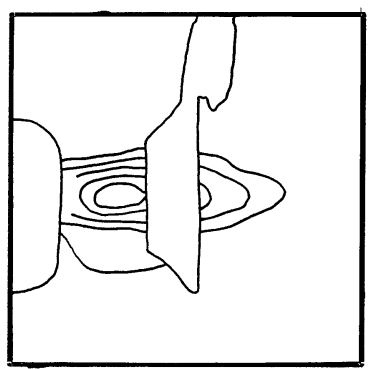

f)

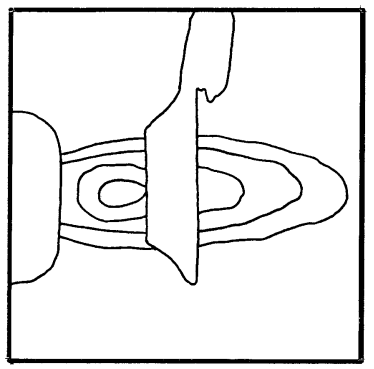

h)

observed fringe shift to line density has been presented in a previous publication ${ }^{14}$ and will not be covered in this article.

\section{EXPERIMENTAL DATA}

Figure 3 shows a laser ablation interferometric density profile time scan of iron neutral atoms. The dye laser is tuned near $\left(\Delta \lambda \equiv \lambda-\lambda_{0}=-0.008 \mathrm{~nm}\right)$ the ground-state neutral iron $\left(\mathrm{Fe} \mathrm{I}^{0}\right)$ transition $\left(\lambda_{0}=271.903 \mathrm{~nm}\right)$ so that all fringe shifts are due to ground-state $\left(a^{5} D\right)$ iron neutral atoms. An offresonance (electron phase shift) time scan was also taken, but no fringe shifting was observed. The time scan presented starts at $400 \mathrm{~ns}$ after the excimer laser strikes the target.

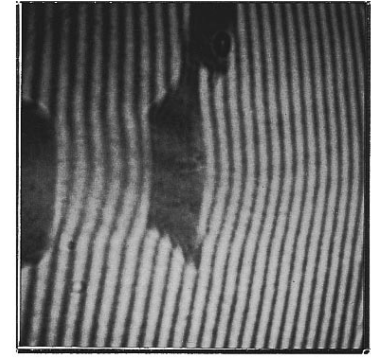

i)

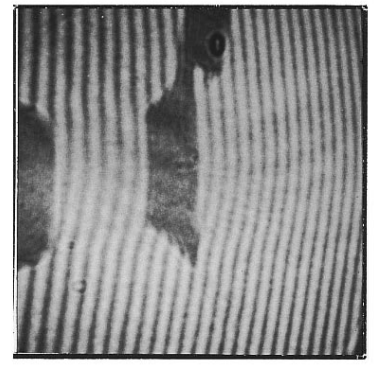

k)

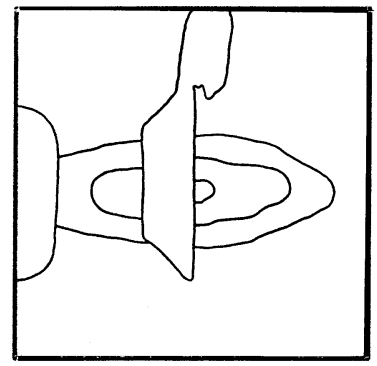

j)

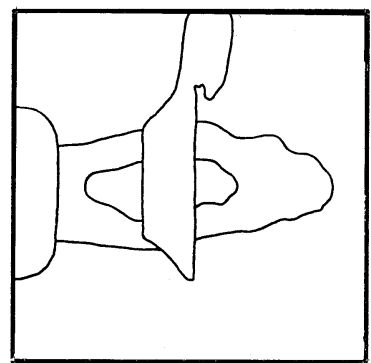

1)
FIG. 3. KrF excimer laser ablation of Fe in vacuum $\left(7.2 \mathrm{~J} / \mathrm{cm}^{2}\right)$ probing near ground-state $\mathrm{Fe}_{\mathrm{I}}^{0}$ neutral $271.903 \mathrm{~nm}$ transition. Time scan showing interferogram and respective equiline-density contour plot. (a) Interferogram at $\Delta \lambda=-0.008 \mathrm{~nm}$ with $400 \mathrm{~ns}$ delay. (b) Equiline-density contours of (a) from outer to inner: $0.25 \mathrm{FS}=9.7 \times 10^{13} \mathrm{~cm}^{-2}, 0.5 \mathrm{FS}=1.9 \times 10^{14}$ $\mathrm{cm}^{-2}, 0.75 \mathrm{FS}=2.9 \times 10^{14} \mathrm{~cm}^{-2}, 1 \mathrm{FS}=3.9 \times 10^{14} \mathrm{~cm}^{-2}$. (c) Interferogram at $\Delta \lambda=-0.008 \mathrm{~nm}$ with $600 \mathrm{~ns}$ delay. (d) Equiline-density contours of (c) from outer to inner: $0.25 \mathrm{FS}=9.7 \times 10^{13} \mathrm{~cm}^{-2}, 0.5 \mathrm{FS}=1.9 \times 10^{14} \mathrm{~cm}^{-2}$, $0.75 \mathrm{FS}=2.9 \times 10^{14} \mathrm{~cm}^{-2}, 1 \mathrm{FS}=3.9 \times 10^{14} \mathrm{~cm}^{-2}, 1.25 \mathrm{FS}=4.9 \times 10^{14}$ $\mathrm{cm}^{-2}, 1.5 \mathrm{FS}=5.9 \times 10^{14} \mathrm{~cm}^{-2}$. (e) Interferogram at $\Delta \lambda=-0.008 \mathrm{~nm}$ with 800 ns delay. (f) Equiline-density contours of (e) from outer to inner: 0.25 $\mathrm{FS}=9.7 \times 10^{13} \mathrm{~cm}^{-2}, 0.5 \mathrm{FS}=1.9 \times 10^{14} \mathrm{~cm}^{-2}, 0.75 \mathrm{FS}=2.9 \times 10^{14} \mathrm{~cm}^{-2}, 1$ $\mathrm{FS}=3.9 \times 10^{14} \mathrm{~cm}^{-2}, 1.25 \mathrm{FS}=4.9 \times 10^{14} \mathrm{~cm}^{-2}$. (g) Interferogram at $\Delta \lambda=$ $-0.008 \mathrm{~nm}$ with $1000 \mathrm{~ns}$ delay. (h) Equiline-density contours of (g) from outer to inner: $0.25 \mathrm{FS}=9.7 \times 10^{13} \mathrm{~cm}^{-2}, 0.5 \mathrm{FS}=1.9 \times 10^{14} \mathrm{~cm}^{-2}, 0.75$ $\mathrm{FS}=2.9 \times 10^{14} \mathrm{~cm}^{-2}, 1 \mathrm{FS}=3.9 \times 10^{14} \mathrm{~cm}^{-2}$. (i) Interferogram at $\Delta \lambda=$ $-0.008 \mathrm{~nm}$ with $1200 \mathrm{~ns}$ delay. (j) Equiline-density contours of (i) from outer to inner: $0.25 \mathrm{FS}=9.7 \times 10^{13} \mathrm{~cm}^{-2}, 0.5 \mathrm{FS}=1.9 \times 10^{14} \mathrm{~cm}^{-2}, 0.75$ $\mathrm{FS}=2.9 \times 10^{14} \mathrm{~cm}^{-2}$. (k) Interferogram at $\Delta \lambda=-0.008 \mathrm{~nm}$ with $1400 \mathrm{~ns}$ delay. (1) Equiline-density contours of (k) from outer to inner: 0.25 $\mathrm{FS}=9.7 \times 10^{13} \mathrm{~cm}^{-2}, 0.5 \mathrm{FS}=1.9 \times 10^{14} \mathrm{~cm}^{-2}$.

Neutral atom interferograms were also taken at a $200 \mathrm{~ns}$ delay, but with no detectable fringe shifting; this is consistent with the plume containing mostly ions at this early time. ${ }^{19}$ The peak Fe I line density occurs at $600 \mathrm{~ns}$ with a measured value of $5.9 \times 10^{14} \mathrm{~cm}^{-2}$. At early times, (400 and $600 \mathrm{~ns}$ ), the region of highest line density is located at the surface of the target. For later times, (800, 1000, 1200, and $1400 \mathrm{~ns})$, the region of highest line density in the plume separates from the surface. Measuring the position of the leading edge of the 0.25 fringe shift $(\mathrm{FS})=9.7 \times 10^{13} \mathrm{~cm}^{-2}$ equiline-density contour at 400 and $600 \mathrm{~ns}$, and assuming zero expansion at time zero, yields a Fe $\mathrm{I}^{0}$ plume expansion velocity of $1.8 \mathrm{~cm} / \mu \mathrm{s}$. 


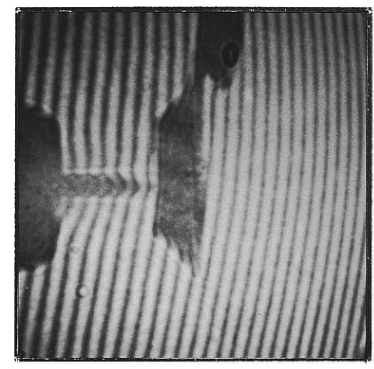

a)

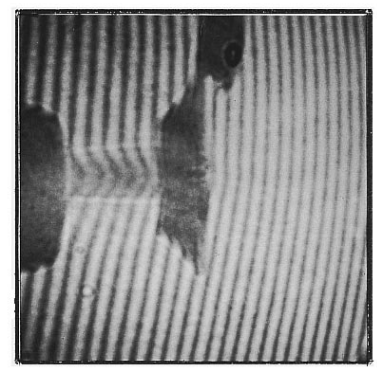

c)

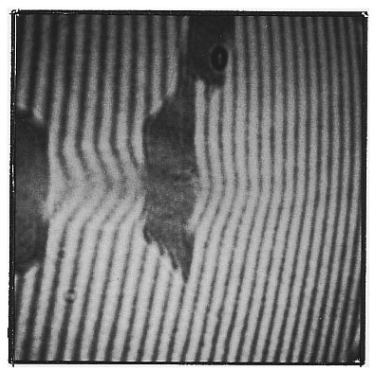

e)

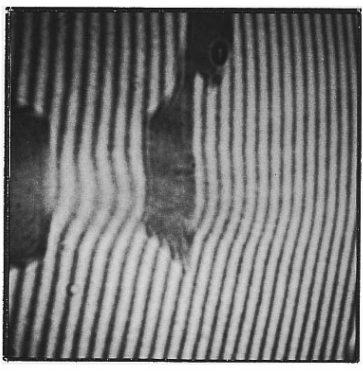

g)

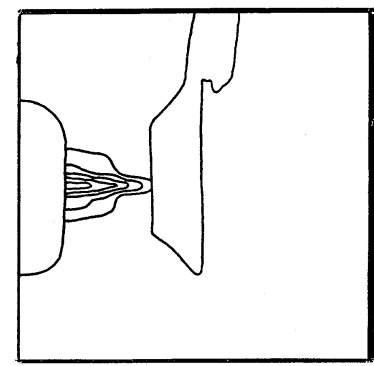

b)

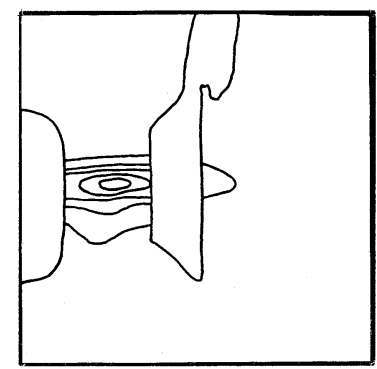

d)

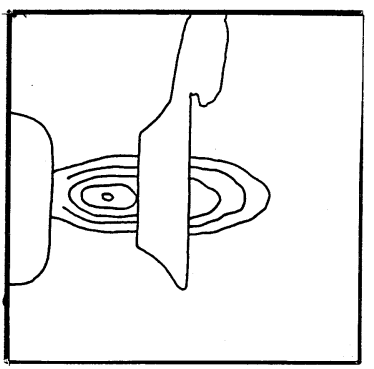

f)

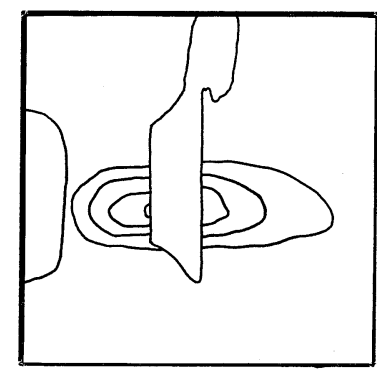

h)
This velocity is similar to higher fluence expansion data of Al atoms using dye-laser-resonance-absorption photography in Ref. 20.

An interferometric time scan for iron neutral atoms generated by the LAAPD is presented in Fig. 4. As in Fig. 3, the dye laser is tuned near $(\Delta \lambda=-0.008 \mathrm{~nm})$ the $\mathrm{Fe} \mathrm{I}^{0}$ $\left(\lambda_{0}=271.903 \mathrm{~nm}\right)$ transition. For consistency and reduction of systematic error, the interferograms in Figs. 3 and 4, for identical delay times, were taken sequentially so the experimental conditions were close to identical for the laser ablation and LAAPD cases. At short delay times of 400 and 600 ns, the interferograms in Figs. 3 and 4 are nearly identical. This is to be expected, since the discharge power is still

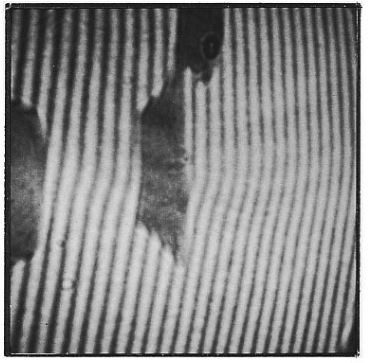

i)

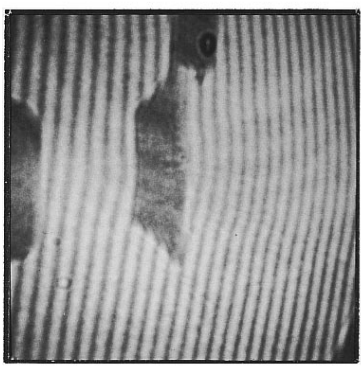

k)

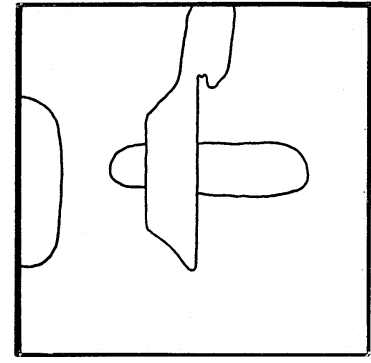

j)

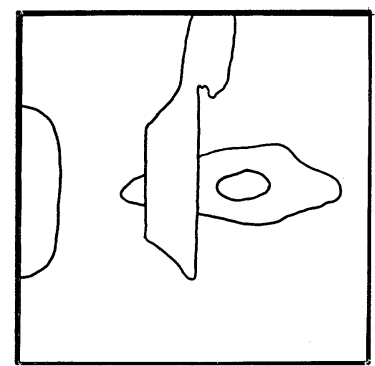

1)

FIG. 4. A $7500 \mathrm{~V}$ LAAPD of Fe in vacuum $\left(7.2 \mathrm{~J} / \mathrm{cm}^{2}\right)$ probing near ground-state $\mathrm{Fe} \mathrm{I}^{0}$ neutral $271.903 \mathrm{~nm}$ transition. Time scan showing interferogram and respective equiline-density contour plot. (a) Interferogram at $\Delta \lambda=-0.008 \mathrm{~nm}$ with $400 \mathrm{~ns}$ delay. (b) Equiline-density contours of (a) from outer to inner: $0.25 \mathrm{FS}=9.7 \times 10^{13} \mathrm{~cm}^{-2}, 0.5 \mathrm{FS}=1.9 \times 10^{14} \mathrm{~cm}^{-2}$, $0.75 \mathrm{FS}=2.9 \times 10^{14} \mathrm{~cm}^{-2}, 1 \mathrm{FS}=3.9 \times 10^{14} \mathrm{~cm}^{-2}, 1.25 \mathrm{FS}=4.9 \times 10^{14}$ $\mathrm{cm}^{-2}$. (c) Interferogram at $\Delta \lambda=-0.008 \mathrm{~nm}$ with $600 \mathrm{~ns}$ delay. (d) Equiline-density contours of (c) from outer to inner: $0.25 \mathrm{FS}=9.7 \times 10^{13}$ $\mathrm{cm}^{-2}, 0.5 \mathrm{FS}=1.9 \times 10^{14} \mathrm{~cm}^{-2}, 0.75 \mathrm{FS}=2.9 \times 10^{14} \mathrm{~cm}^{-2}, 1 \mathrm{FS}=3.9 \times 10^{14}$ $\mathrm{cm}^{-2}, 1.25 \mathrm{FS}=4.9 \times 10^{14} \mathrm{~cm}^{-2}$. (e) Interferogram at $\Delta \lambda=-0.008 \mathrm{~nm}$ with 800 ns delay. (f) Equiline-density contours of (e) from outer to inner: $0.25 \mathrm{FS}=9.7 \times 10^{13} \mathrm{~cm}^{-2}, 0.5 \mathrm{FS}=1.9 \times 10^{14} \mathrm{~cm}^{-2}, 0.75 \mathrm{FS}=2.9 \times 10^{14}$ $\mathrm{cm}^{-2}, 1 \mathrm{FS}=3.9 \times 10^{14} \mathrm{~cm}^{-2}, 1.25 \mathrm{FS}=4.9 \times 10^{14} \mathrm{~cm}^{-2}$. (g) Interferogram at $\Delta \lambda=-0.008 \mathrm{~nm}$ with $1000 \mathrm{~ns}$ delay. (h) Equiline-density contours of (g) from outer to inner: $0.25 \mathrm{FS}=9.7 \times 10^{13} \mathrm{~cm}^{-2}, 0.5 \mathrm{FS}=1.9 \times 10^{14} \mathrm{~cm}^{-2}$, $0.75 \mathrm{FS}=2.9 \times 10^{14} \mathrm{~cm}^{-2}, 1 \mathrm{FS}=3.9 \times 10^{14} \mathrm{~cm}^{-2}$. (i) Interferogram at $\Delta \lambda$ $=-0.008 \mathrm{~nm}$ with $1200 \mathrm{~ns}$ delay. (j) Equiline-density contours of (i) from outer to inner: $0.25 \mathrm{FS}=9.7 \times 10^{13} \mathrm{~cm}^{-2}$. (k) Interferogram at $\Delta \lambda=-0.008$ $\mathrm{nm}$ with $1400 \mathrm{~ns}$ delay. (1) Equiline-density contours of (k) from outer to inner: $0.25 \mathrm{FS}=9.7 \times 10^{13} \mathrm{~cm}^{-2}, 0.5 \mathrm{FS}=1.9 \times 10^{14} \mathrm{~cm}^{-2}$.

increasing and initially has minimal effect on the ablated material. After $800 \mathrm{~ns}$, a slight depletion of $\mathrm{Fe} \mathrm{I}^{0}$ atoms near the target surface is observed with application of the discharge; this can be seen by comparing the fringe shifting in Figs. 4(f) and 3(f). For later times (1000, 1200, and $1400 \mathrm{ns)}$ near the peak of the discharge power, the Fe $\mathrm{I}^{0}$ neutral depletion effect is more dramatic as the $\mathrm{Fe} \mathrm{I}^{0}$ plume separates from the surface [Figs. 4(h)-4(1)], while the Fe $\mathrm{I}^{0}$ plume, with laser ablation only, is still in contact with the surface [Figs. 3(h)-3(1)]. Furthermore the peak detectable line density of $\mathrm{Fe} \mathrm{I}^{0}$ atoms between the electrode and target decreases for the LAAPD case; this is consistent with the discharge power heating the iron plume, producing excited-state neutrals and 


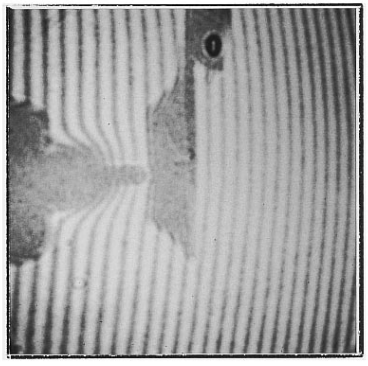

a)

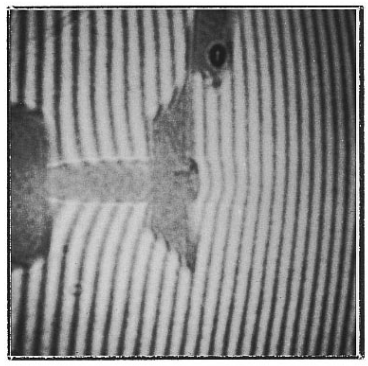

c)

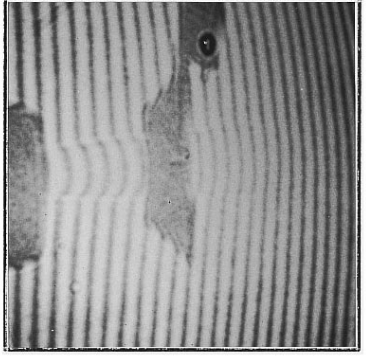

e)

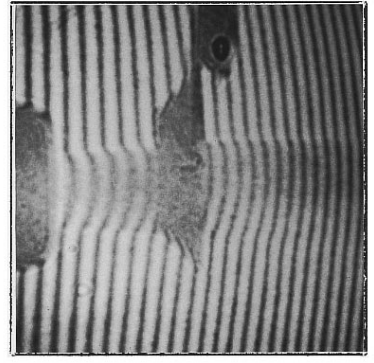

g)

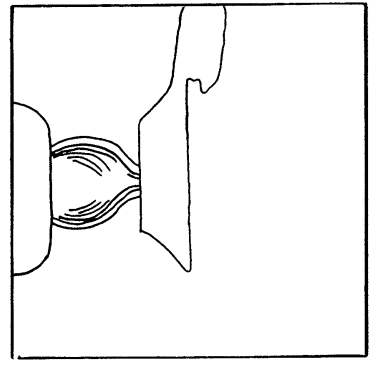

b)

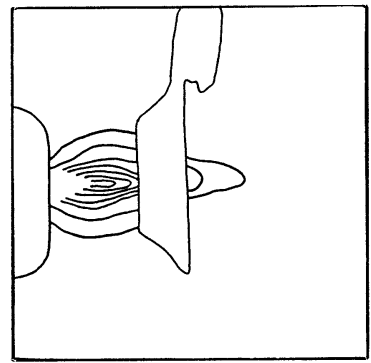

d)

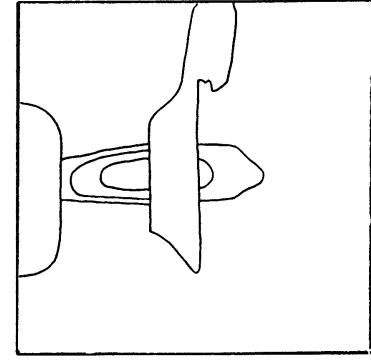

f)

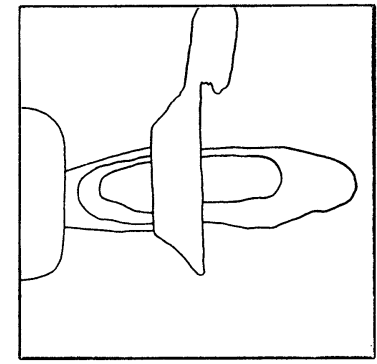

h)
$1 \mathrm{~cm}$

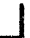

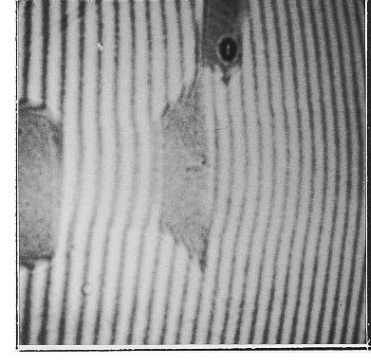

i)

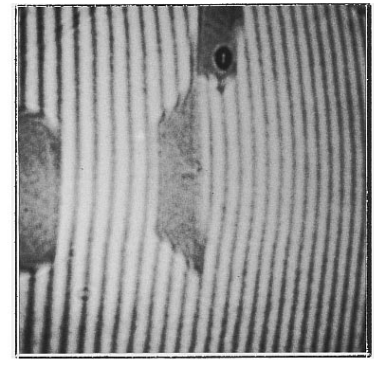

$\mathrm{k})$

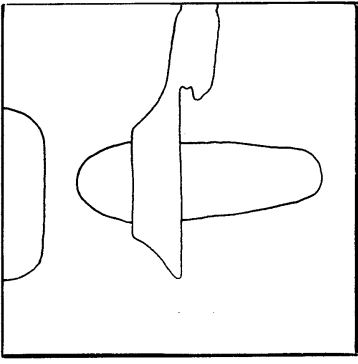

j)

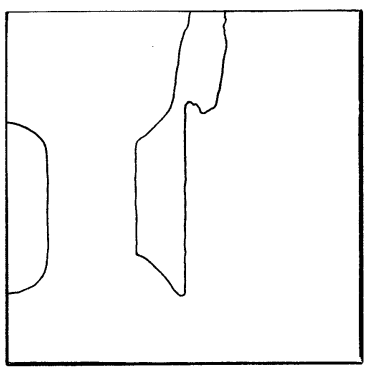

1)
FIG. 5. $\mathrm{KrF}$ excimer laser ablation of $\mathrm{Fe}$ in vacuum $\left(6.9 \mathrm{~J} / \mathrm{cm}^{2}\right)$ probing near excited-state $\mathrm{Fe} \mathrm{II}^{*}$ single-ion $273.955 \mathrm{~nm}$ transition. Time scan showing interferogram and respective equiline-density contour plot. (a) Interferogram at $\Delta \lambda=-0.016 \mathrm{~nm}$ with $200 \mathrm{~ns}$ delay. (b) Equiline-density contours of (a) from outer to inner: $0.25 \mathrm{FS}=1.1 \times 10^{14} \mathrm{~cm}^{-2}, 0.5$ $\mathrm{FS}=2.1 \times 10^{14} \mathrm{~cm}^{-2}, 0.75 \mathrm{FS}=3.2 \times 10^{14} \mathrm{~cm}^{-2}, 1 \mathrm{FS}=4.3 \times 10^{14} \mathrm{~cm}^{-2}, 1.5$ $\mathrm{FS}=6.4 \times 10^{14} \mathrm{~cm}^{-2}, 2 \mathrm{FS}=8.6 \times 10^{14} \mathrm{~cm}^{-2}$. (c) Interferogram at $\Delta \lambda=$ $-0.016 \mathrm{~nm}$ with $400 \mathrm{~ns}$ delay. (d) Equiline-density contours of (c) from outer to inner: $0.25 \mathrm{FS}=1.1 \times 10^{14} \mathrm{~cm}^{-2}, 0.5 \mathrm{FS}=2.1 \times 10^{14} \mathrm{~cm}^{-2}, 0.75$ $\mathrm{FS}=3.2 \times 10^{14} \mathrm{~cm}^{-2}, 1 \mathrm{FS}=4.3 \times 10^{14} \mathrm{~cm}^{-2}, 1.5 \mathrm{FS}=6.4 \times 10^{14} \mathrm{~cm}^{-2}, 2$ $\mathrm{FS}=8.6 \times 10^{14} \mathrm{~cm}^{-2}, 2.5 \mathrm{FS}=1.1 \times 10^{15} \mathrm{~cm}^{-2}$. (e) Interferogram at $\Delta \lambda=$ $-0.016 \mathrm{~nm}$ with $600 \mathrm{~ns}$ delay. (f) Equiline-density contours of (e) from outer to inner: $0.25 \mathrm{FS}=1.1 \times 10^{14} \mathrm{~cm}^{-2}, 0.5 \mathrm{FS}=2.1 \times 10^{14} \mathrm{~cm}^{-2}, 0.75$ $\mathrm{FS}=3.2 \times 10^{14} \mathrm{~cm}^{-2}$. (g) Interferogram at $\Delta \lambda=-0.009 \mathrm{~nm}$ with $800 \mathrm{~ns}$ delay. (h) Equiline-density contours of $(\mathrm{g})$ from outer to inner: 0.25 $\mathrm{FS}=5.9 \times 10^{13} \mathrm{~cm}^{-2}, 0.5 \mathrm{FS}=1.2 \times 10^{14} \mathrm{~cm}^{-2}, 0.75 \mathrm{FS}=1.8 \times 10^{14} \mathrm{~cm}^{-2}$. (i) Interferogram at $\Delta \lambda=-0.009 \mathrm{~nm}$ with $1000 \mathrm{~ns}$ delay. (j) Equilinedensity contours of (i) from outer to inner: $0.25 \mathrm{FS}=5.9 \times 10^{13} \mathrm{~cm}^{-2}$. (k) Interferogram at $\Delta \lambda=-0.009 \mathrm{~nm}$ with $1200 \mathrm{~ns}$ delay with (1) showing no detectable fringe shift. ions. The ground-state $\mathrm{Fe} \mathrm{I}^{0}$ atoms are most noticeably depleted near the target, as expected, since the electric field, current density, and plume density are highest in this region.

The ionization dynamics of laser ablation and LAAPD were also investigated by probing the density of Fe II ions. Figure 5 shows an interferometric time scan for iron laser ablation, using the excited-state iron single ion (Fe II*) transition $\left(\lambda_{0}=273.955 \mathrm{~nm}\right)$ with fringe shift due to ions in the $a^{4} D$ state. For this time scan, the dye laser was tuned to $\Delta \lambda=-0.009 \mathrm{~nm}$ for delay times $\geqslant 800 \mathrm{~ns}$, while for earlier times, $\Delta \lambda=-0.016 \mathrm{~nm}$ was used to reduce absorption of the dye laser beam. In comparison to Fig. 3, this time scan starts at a $200 \mathrm{~ns}$ delay demonstrating that for early times $(<200$ ns), the plume consists mostly of ions (Fe II). The peak, detectable $\mathrm{Fe} \mathrm{II}^{*}$ line density occurs at $400 \mathrm{~ns}$ with a measured value of $1.1 \times 10^{15} \mathrm{~cm}^{-2}$. However, the peak line density is likely higher, but absorption near the plume center made determination of the fringe shift impossible. At early times (200 and $400 \mathrm{~ns}$ ), the region of highest Fe II ${ }^{*}$ ion density is in contact with the target surface, while for later times, $(600$, 800,1000 , and $1200 \mathrm{~ns}$ ) the ionic plume (ions in the $a^{4} D$ state) starts to separate from the surface. By measuring the position of the leading edge of the $0.25 \mathrm{FS}=1.1 \times 10^{14} \mathrm{~cm}^{-2}$ equiline-density contour at 400 and $600 \mathrm{~ns}$ (and assuming zero expansion at time zero), the expansion velocity of the $\mathrm{Fe} \mathrm{II}^{*}$ ions in the plume is calculated to be $3.5 \mathrm{~cm} / \mu \mathrm{s}$. Note 


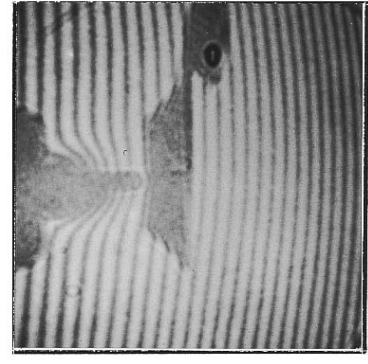

a)

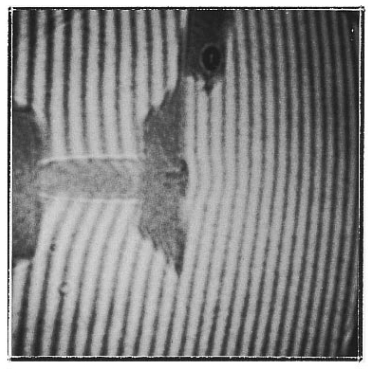

c)

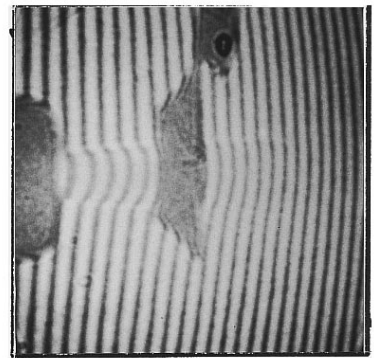

e)

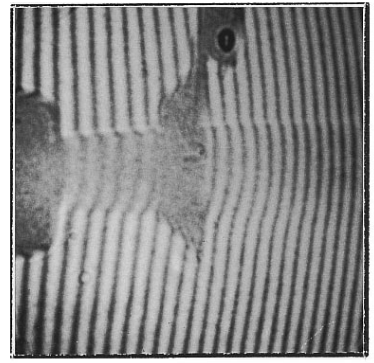

g)

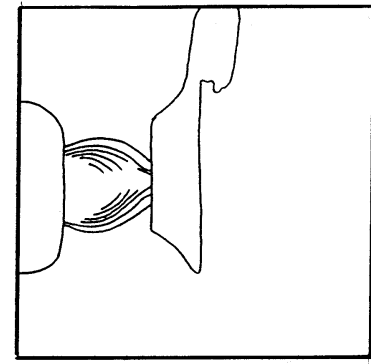

b)

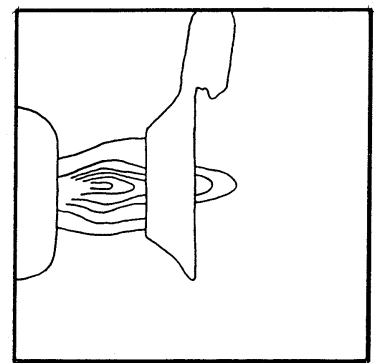

d)

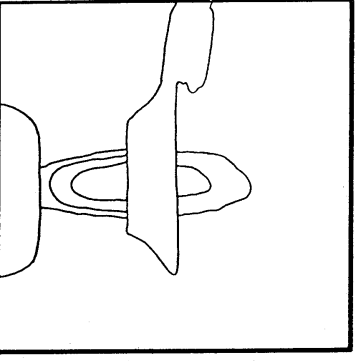

f)

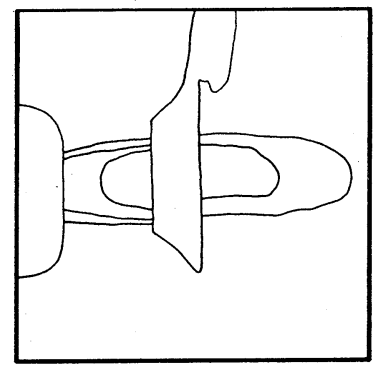

h) that for a $200 \mathrm{~ns}$ delay, this equiline-density contour is behind the ring electrode, so that position could not be measured and included for calculation of the expansion velocity. The significantly higher expansion velocity of ions (overneutrals) could be due to their acceleration by the ambipolar electric field present at early times. ${ }^{19}$ Measurement of the ionization effect of the LAAPD is presented in Fig. 6, in which the interferogram time scan probed the same excitedstate Fe II* $\left(\lambda_{0}=273.955 \mathrm{~nm}\right)$ transition used in Fig. 5. Similar to Figs. 3 and 4, the interferograms of Figs. 5 and 6 were taken sequentially for identical delay times. At early times (200, 400, and $600 \mathrm{~ns}$ ), the LAAPD interferograms appear similar to the corresponding laser ablation interferograms in

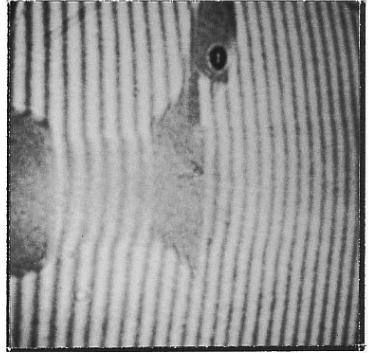

i)

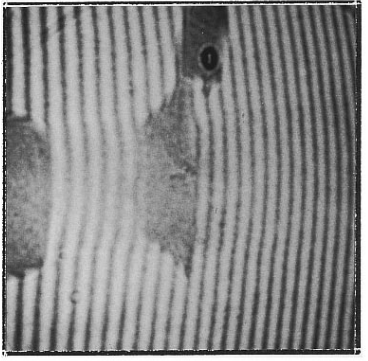

k)

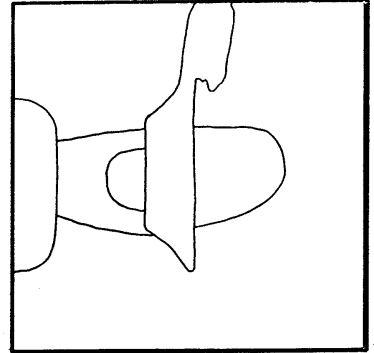

j)
FIG. 6. A $7500 \mathrm{~V}$ LAAPD of Fe in vacuum $\left(6.9 \mathrm{~J} / \mathrm{cm}^{2}\right)$ probing near excited-state $\mathrm{Fe} \mathrm{II}^{*}$ single-ion $273.955 \mathrm{~nm}$ transition. Time scan showing interferogram and respective equiline-density contour plot. (a) Interferogram at $\Delta \lambda=-0.016 \mathrm{~nm}$ with $200 \mathrm{~ns}$ delay. (b) Equiline-density contours of (a) from outer to inner: $0.25 \mathrm{FS}=1.1 \times 10^{14} \mathrm{~cm}^{-2}, 0.5 \mathrm{FS}=2.1 \times 10^{14}$ $\mathrm{cm}^{-2}, 0.75 \mathrm{FS}=3.2 \times 10^{14} \mathrm{~cm}^{-2}, 1 \mathrm{FS}=4.3 \times 10^{14} \mathrm{~cm}^{-2}, 1.5 \mathrm{FS}=6.4 \times 10^{14}$ $\mathrm{cm}^{-2}, 2 \mathrm{FS}=8.6 \times 10^{14} \mathrm{~cm}^{-2}$. (c) Interferogram at $\Delta \lambda=0.016 \mathrm{~nm}$ with 400 ns delay. (d) Equiline-density contours of (c) from outer to inner: 0.25 $\mathrm{FS}=1.1 \times 10^{14} \mathrm{~cm}^{-2}, 0.5 \mathrm{FS}=2.1 \times 10^{14} \mathrm{~cm}^{-2}, 0.75 \mathrm{FS}=3.2 \times 10^{14} \mathrm{~cm}^{-2}, 1$ $\mathrm{FS}=4.3 \times 10^{14} \mathrm{~cm}^{-2}, 1.5 \mathrm{FS}=6.4 \times 10^{14} \mathrm{~cm}^{-2}, 2 \mathrm{FS}=8.6 \times 10^{14} \mathrm{~cm}^{-2}$. (e) Interferogram at $\Delta \lambda=-0.016 \mathrm{~nm}$ with $600 \mathrm{~ns}$ delay. (f) Equiline-density contours of (e) from outer to inner: $0.25 \mathrm{FS}=1.1 \times 10^{14} \mathrm{~cm}^{-2}, 0.5$ $\mathrm{FS}=2.1 \times 10^{14} \mathrm{~cm}^{-2}, 0.75 \mathrm{FS}=3.2 \times 10^{14} \mathrm{~cm}^{-2}$. (g) Interferogram at $\Delta \lambda=$ $-0.009 \mathrm{~nm}$ with $800 \mathrm{~ns}$ delay. (h) Equiline-density contours of (g) from outer to inner: $0.25 \mathrm{FS}=5.9 \times 10^{13} \mathrm{~cm}^{-2}, 0.5 \mathrm{FS}=1.2 \times 10^{14} \mathrm{~cm}^{-2}, 0.75$ $\mathrm{FS}=1.8 \times 10^{14} \mathrm{~cm}^{-2}$. (i) Interferogram at $\Delta \lambda=-0.009 \mathrm{~nm}$ with $1000 \mathrm{~ns}$ delay. (j) Equiline-density contours of (i) from outer to inner: 0.25 $\mathrm{FS}=5.9 \times 10^{13} \mathrm{~cm}^{-2}, 0.5 \mathrm{FS}=1.2 \times 10^{14} \mathrm{~cm}^{-2}$. (k) Interferogram at $\Delta \lambda=$ $-0.009 \mathrm{~nm}$ with $1200 \mathrm{~ns}$ delay. (1) Equiline-density contours of (k) from outer to inner: $0.25 \mathrm{FS}=5.9 \times 10^{13} \mathrm{~cm}^{-2}, 0.5 \mathrm{FS}=1.2 \times 10^{14} \mathrm{~cm}^{-2}$.
Fig. 5. Again, this is to be expected, since the discharge power is still increasing and the discharge current is low. However, at $800 \mathrm{~ns}$, the Fe II $0.5 \mathrm{FS}\left(1.2 \times 10^{14} \mathrm{~cm}^{-2}\right)$ equiline-density contour of the LAAPD in Fig. 6(h) extends to the target surface, while with laser ablation only in Fig. 5 (h), only the Fe II $0.25 \mathrm{FS}\left(5.9 \times 10^{13} \mathrm{~cm}^{-2}\right)$ equilinedensity contour is in contact with the surface, corresponding to a doubling of this excited-state ion density at the surface. At later times (1000 and $1200 \mathrm{~ns}$ ), the effect of the discharge is more pronounced. With laser ablation only, no detectable Fe II ${ }^{*}$ fringe shifting $\left(\leqslant 0.25 \mathrm{FS}\right.$ or $\left.\leqslant 5.9 \times 10^{13} \mathrm{~cm}^{-2}\right)$ is observed at $1200 \mathrm{~ns}$ [Fig. 5(1)], but with the discharge, 0.5 FS $\left(1.2 \times 10^{14} \mathrm{~cm}^{-2}\right)$ is detectable [Fig. 6(1)]. The major effect of 

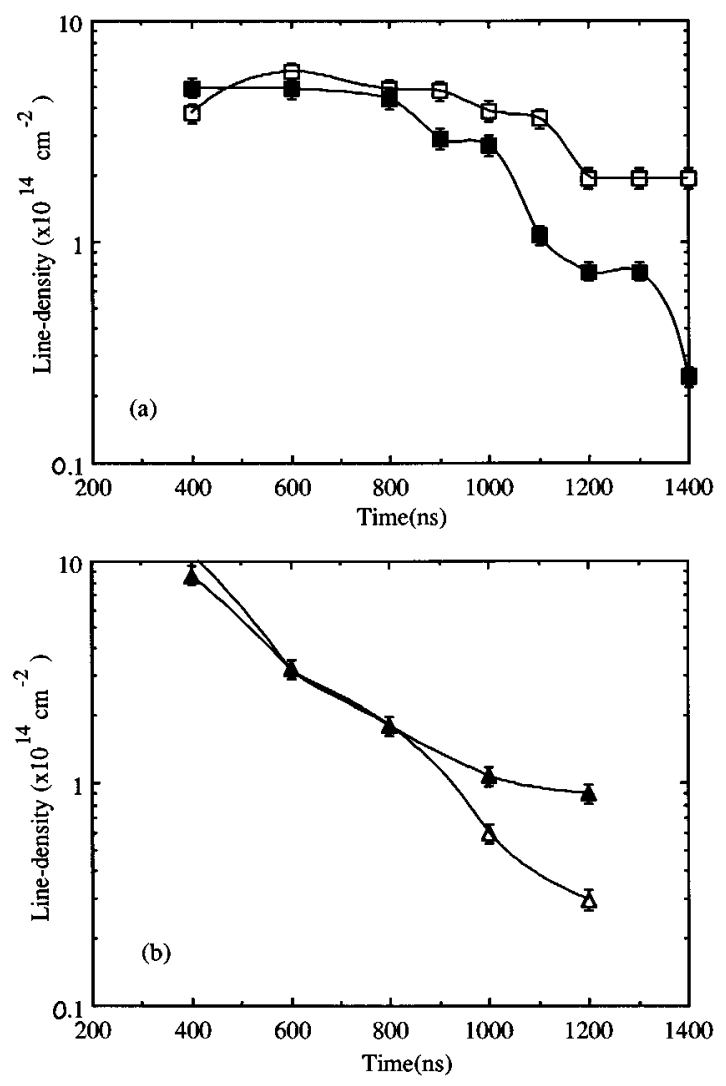

FIG. 7. Absolute line density in center of electrode-target gap for: (a) ground-state $\mathrm{Fe} \mathrm{I}^{0}\left(a^{5} D\right)$ atoms from $(\square)$ laser ablation and $(\square) 7500 \mathrm{~V}$ LAAPD; (b) excited-state $\mathrm{Fe}$ II* $\left(a^{4} D, 0.99 \mathrm{eV}\right.$ above ground) ions from $(\triangle)$ laser ablation and $(\boldsymbol{\Delta}) 7500 \mathrm{~V}$ LAAPD.

the discharge is to increase the number of ions in the plume through ionization of iron neutral atoms.

\section{DATA ANALYSIS AND DISCUSSION}

The discharge effect on the iron laser ablation plume is further quantified in Fig. 7, by plotting the interferometric line density (from Figs. 3-6) as a function of time at the center of the electrode-target gap for both the $\mathrm{Fe} \mathrm{I}^{0}$ and Fe II* species, with and without the discharge. Note that for the later times (1200 and $1400 \mathrm{~ns}$ ), in some cases, less than 0.25 fringe shift $\left(\sim 1 \times 10^{14} \mathrm{~cm}^{-2}\right)$ was observed; for these interferograms, the minimum detectable fringe shift was lowered to $0.125 \mathrm{FS}\left(\sim 5 \times 10^{13} \mathrm{~cm}^{-2}\right)$. As mentioned in the previous paragraph, the $\mathrm{Fe} \mathrm{I}^{0}$ atom line density at the gap center, as shown in Fig. 7(a), changes little for times less than $800 \mathrm{~ns}$, comparing laser ablation to the discharge case. At later times, $1200 \mathrm{~ns}$ for example, a factor of $\sim 2.6$ reduction in the $\mathrm{Fe} \mathrm{I}^{0}$ atom line density at the center of the electrode-target gap is observed with the presence of the LAAPD.

Figure 7(b) further illustrates the $\mathrm{Fe} \mathrm{II}^{*}$ line density (taken from Figs. 3-6) at the center of the electrode-target gap as a function of time for laser ablation and the LAAPD. Again, the discharge has little effect for times less than 800 ns where the discharge current is low. However, at $1200 \mathrm{~ns}$, the Fe II* line density has increased by a factor of 3 with the
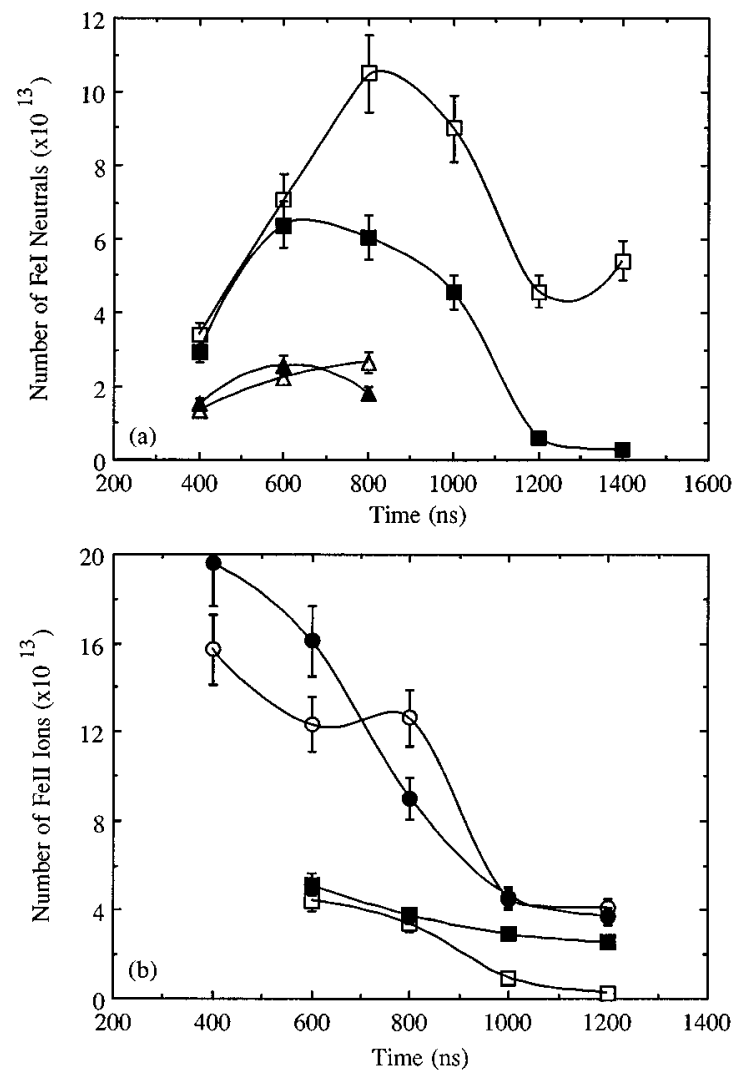

FIG. 8. Population number between electrode and target for: (a) $\mathrm{Fe}^{0}\left(a^{5} D\right)$ atoms from ( $\square$ ) laser ablation and (ם) $7500 \mathrm{~V}$ LAAPD; Fe I* $\left(a^{5} F, 0.86 \mathrm{eV}\right.$ above ground) atoms from $(\triangle)$ laser ablation and $(\mathbf{\Delta}) 7500$ V LAAPD; (b) Fe II* ions $\left(a^{6} D, 0.11 \mathrm{eV}\right.$ above ground) from $(\bigcirc)$ laser ablation and $(\bullet)$ $7500 \mathrm{~V}$ LAAPD, Fe II* ions ( $a^{4} D, 0.99 \mathrm{eV}$ above ground) from $(\square)$ laser ablation and (ם) 7500 V LAAPD.

discharge compared to laser ablation only. From Fig. 2, the instantaneous discharge power (the product of discharge current and voltage) is close to maximum (1.3 MW) at $1200 \mathrm{ns,}$ thus heating the plume and yielding an increased number of ions.

To estimate the ionization fraction in the laser-ablation plume and the discharge, the total number of neutrals and ions needs to be calculated. Since interferogram time scans were taken with two different transitions (only interferograms for one transition have been shown) for both iron neutrals and ions, the total number of iron neutral atoms or ions can be determined by assuming a Boltzmann population distribution. This involves converting the interferogram linedensity profiles to the number of species. Since the ring electrode obstructs part of the plume, only the region between the electrode and target is considered. The total number of neutral atoms or ions, in a given state, is determined by tracing the equiline-density contours onto graph paper, counting up the area between the contours, multiplying by the outer line-density contour, and summing the result from each area. This assumes a stepwise density profile and produces a lower bound estimate for the number of neutral atoms or ions for the population of interest.

Summaries are given in Fig. 8(a) of the number of ground-state $\mathrm{Fe} \mathrm{I}^{0}\left(\lambda_{0}=271.903 \mathrm{~nm}\right)$ and excited-state $\mathrm{Fe} \mathrm{I}^{*}$ 


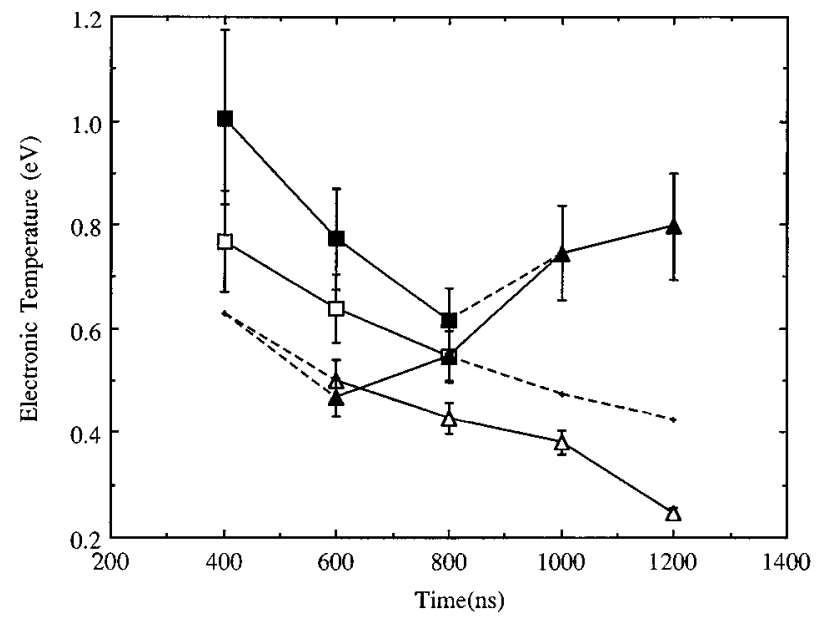

FIG. 9. Inferred electronic temperature for Fe I with ( $\square$ ) laser ablation and (ם) $7500 \mathrm{~V}$ LAAPD, and for Fe II with $(\triangle)$ laser ablation and $(\boldsymbol{\Delta}) 7500 \mathrm{~V}$ LAAPD assuming a Boltzmann population distribution. Dashed lines represent extrapolated temperature assumptions.

$\left(\lambda_{0}=273.358 \mathrm{~nm}, 0.86 \mathrm{eV}\right)$ atoms between the electrode and target as a function of time for laser ablation and the LAAPD. For times less than $600 \mathrm{~ns}$, the discharge has little effect and the numbers of both Fe I species are increasing,
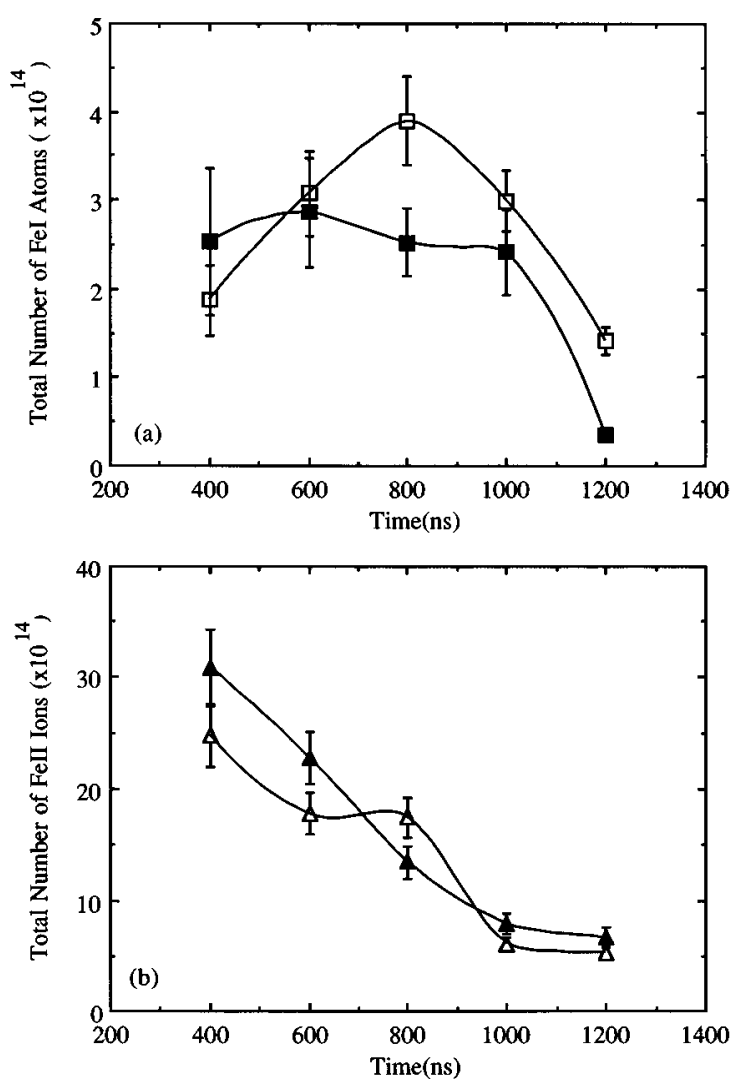

FIG. 10. Total number of neutral atoms or ions between electrode and target for (a) Fe I with ( $\square$ ) laser ablation and (ם) $7500 \mathrm{~V} \mathrm{LAAPD,} \mathrm{and} \mathrm{for} \mathrm{(b)} \mathrm{Fe} \mathrm{II}$ with $(\triangle)$ laser ablation and $(\mathbf{\Delta}) 7500 \mathrm{~V}$ LAAPD assuming a Boltzmann population distribution.

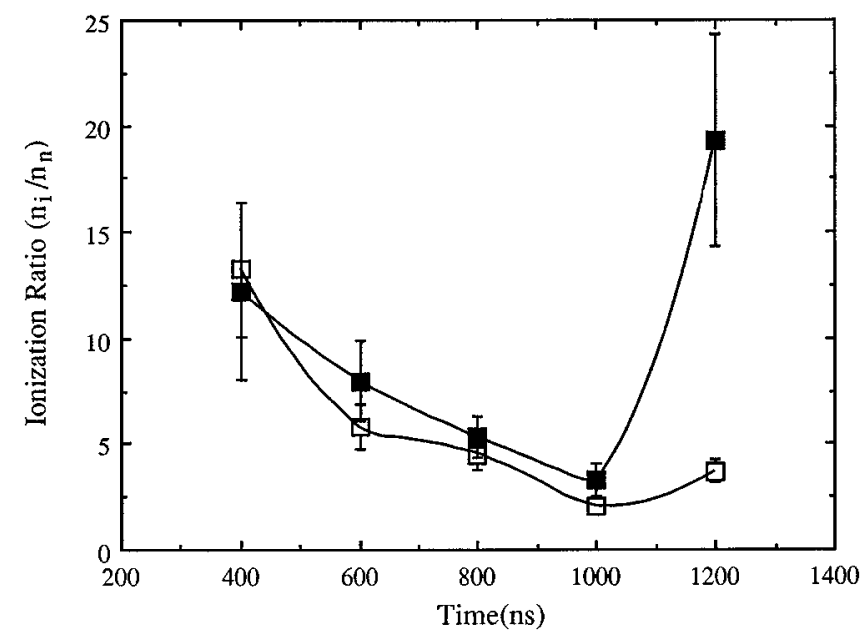

FIG. 11. Ionization ratio defined as the number of Fe II ions divided by the number of Fe I neutrals for ( $\square$ ) laser ablation and (ם) 7500 V LAAPD.

although there are fewer excited state neutrals as consistent with an equilibrium distribution. The discharge's depletion of ground-state $\mathrm{Fe} \mathrm{I}^{0}$ atoms is clearly illustrated for times greater than $800 \mathrm{~ns}$. By $1200 \mathrm{~ns}$, the number of ground-state $\mathrm{Fe} \mathrm{I}^{0}$ atoms between the electrode and target has been reduced by a factor of $\sim 7.7$ by the LAAPD. Due to reduced diagnostic sensitivity using the excited-state $\mathrm{Fe} \mathrm{I}^{*}$ transition, the number of this population could not be calculated for times greater than $800 \mathrm{~ns}$; however, with application of the discharge, a small reduction in the population number is observed.

Figure $8(\mathrm{~b})$ shows the total number of excited-state $\mathrm{Fe} \mathrm{II}^{*}$ ions, for both transitions used, between the electrode and target as a function of time for laser ablation and the LAAPD. The lower energy level $(0.11 \mathrm{eV})$ excited-state Fe II* ion $(263.105 \mathrm{~nm})$ population increases slightly with application of the discharge prior to $600 \mathrm{~ns}$, presumably due to the electrode-target gap electric field enhancing electron collisions and excitation. At $800 \mathrm{~ns}$, the reduced population of these ions, with application of the discharge, may be indicative of removal of the laser-ablated ions from the electrode-target gap by the electric field prior to the discharge converting neutral atoms to ions. With the higher energy level $(0.99 \mathrm{eV})$ excited-state Fe II* $(273.955 \mathrm{~nm})$ population, the discharge has no effect before $800 \mathrm{~ns}$. Closer to the power maximum (1000 ns) it can be seen with the discharge, that the population of the lower energy level remains unchanged, while the higher energy level population increases, indicating the total number of ions has been increased.

Assuming a Boltzmann population distribution, the inferred iron neutral (Fe I) and ion (Fe II) electronic temperatures are presented in Fig. 9 as a function of time with laser ablation only versus the LAAPD. The neutral Fe I electronic temperature could not be determined beyond $800 \mathrm{~ns}$ as the excited-state $\mathrm{Fe} \mathrm{I}^{*}$ transition provided low sensitivity yielding no detectable fringe shifting. Similarly, interferograms probing the excited-state $\mathrm{Fe} \mathrm{II}^{*}(263.105 \mathrm{~nm})$ transition produced significant absorption at $400 \mathrm{~ns}$, rendering a reliable 
calculation of the number of this population impossible. Hence, the singly ionized Fe II electronic temperature could not be determined at $400 \mathrm{~ns}$. Figure 9 indicates that the neutral Fe I temperature decreases with time for both laser ablation and the LAAPD, but the magnitude of the temperature with the discharge is higher. The higher temperature with the LAAPD can be attributed to the discharge inhibiting recombination, resulting in more electron-atom collisions, and heating the plume. The singly ionized Fe II electronic temperature in Fig. 9 is also observed to decrease with time for laser ablation only, while this temperature increases with application of the discharge.

The ionization ratio in the volume between the electrode and target can be estimated by dividing the total number of Fe II ions by the total number of Fe I neutral atoms. This assumes that the population of higher charge-state ions is small, which is consistent with local thermodynamic equilibrium (LTE) and the temperatures of Fig. 9. With interferograms taken at two different transition energy levels for the neutral and the ion, the total number of neutrals and singly charged ions can be calculated. This assumes the species population follows a Boltzmann distribution and requires the number of a given population species, the electronic temperature, and knowledge of the species partition function. Figure 10 shows the estimated total number of iron neutral atoms and singly ionized atoms between the ring electrode and target, where the temperature of the neutral atoms from laser ablation is extrapolated from 800 to $1200 \mathrm{~ns}$ and the neutral atom temperature in the discharge is assumed to take on the ion temperature for the same time frame. Similarly, the ion temperature from 400 to $600 \mathrm{~ns}$, for both the laser ablation and discharge cases, is assumed to follow the shape of the neutral temperature as the discharge has minimal effect at these times. For laser ablation only (at these high fluences of $\sim 7 \mathrm{~J} / \mathrm{cm}^{2}$ ), the ionization ratio plotted in Fig. 11 indicates that the plume is highly ionized. The decreasing ionization ratio with time (from 400 to $1000 \mathrm{~ns}$ ) is likely the result of ion loss due to recombination, ambipolar diffusion, ${ }^{19}$ and loss of ions from the volume between the target and electrode due to the higher ion expansion velocity. With application of the discharge, the ionization ratio increases by a factor of $\sim 5$ at $1200 \mathrm{~ns}$ (near the peak in the discharge power), thus proving the LAAPD increases the plume ionization.

In conclusion, the ionization dynamics of laser ablation and a LAAPD ion source have been investigated with a newly developed, dye-laser-based resonant interferometry diagnostic. The absolute line-density profiles of two iron neutral and single ion populations have been measured. This allows the neutral and ion electronic temperature, total number of each species, and the ionization ratio to be calculated assuming a Boltzmann distribution. With the high laser fluences used in this work $\left(\sim 7 \mathrm{~J} / \mathrm{cm}^{2}\right)$, the laser ablation plume ionization ratio at $1200 \mathrm{~ns}$ is approximately 3 . The iron neutral electronic temperature is observed to be higher than the ion electronic temperature and both decrease with time rapidly. With application of the discharge, the ion electronic temperature increases to around $0.8 \mathrm{eV}$, consistent with previous work, ${ }^{18}$ and the ionization ratio increases by a factor of $\sim 5$ to approximately 20 .

\section{ACKNOWLEDGMENTS}

This research is supported by National Science Foundation Grant No. CTS-9108971. J. S. L. and H. L. S. acknowledge the National Science Foundation for Graduate Fellowships.

${ }^{1}$ G. L. Doll, J. A. Sell, C. A. Taylor, and R. Clarke, Phys. Rev. B. 43, 6816 (1991).

${ }^{2}$ R. W. Dreyfus, J. Appl. Phys. 69, 1721 (1991).

${ }^{3}$ J. T. Dickinson, S. C. Langford, J. J. Shin, and D. L. Doering, Phys. Rev. Lett. 73, 2630 (1994).

${ }^{4}$ J. T. Dickinson, S. C. Langford, L. C. Jensen, P. A. Eschbach, L. R. Pederson, and D. R. Baer, J. Appl. Phys. 68, 1831 (1990).

${ }^{5}$ J. S. Meachum, Ph.D. thesis, University of Michigan, Ann Arbor, MI, 1988.

${ }^{6}$ A. D. Sappey and T. K. Gamble, Appl. Phys. B 53, 353 (1991).

${ }^{7}$ D. B. Geohegan and D. N. Mashburn, Appl. Phys. Lett. 55, 2345 (1989).

${ }^{8} \mathrm{~K}$. Murakami, in Laser Ablation of Electronic Materials, edited by E. Fogarassy and S. Lazare (Elseviere Amsterdam, 1992), p. 125.

${ }^{9}$ A. D. Sappey, T. K. Gamble, and D. K. Zirkle, Appl. Phys. Lett. 62, 564 (1993).

${ }^{10}$ R. E. Walkup, J. M. Jasinski, and R. W. Dreyfus, Appl. Phys. Lett. 48, 1690 (1986).

${ }^{11}$ D. K. Koopman, H. J. Siebeneck, and G. Jellison, Phys. Fluids 22, 526 (1979).

${ }^{12}$ G. V. Dreiden, A. N. Zaidel', G. B. Ostrovskaya, Y. I. Ostrovskii, N. A. Pobedonostseva, L. V. Tanin, V. N. Filippov, and E. N. Shedova, Sov. J. Plasma Phys. 1, 256 (1975).

${ }^{13}$ R. A. Lindley, R. M. Gilgenbach, and C. H. Ching, Appl. Phys. Lett. 63, 888 (1993).

${ }^{14}$ R. A. Lindley, R. M. Gilgenbach, C. H. Ching, J. S. Lash, and G. L. Doll, J. Appl. Phys. 76, 5457 (1994).

${ }^{15}$ H. J. Odenthal and J. Uhlenbusch, IEEE Trans. Plasma Sci. PS-8, 431 (1980).

${ }^{16}$ W. D. Kimura, M. J. Kushner, E. A. Crawford, and S. R. Byron, IEEE Trans. Plasma Sci. PS-14, 246 (1986).

${ }^{17}$ J. S. Lash, R. M. Gilgenbach, and C. H. Ching, Appl. Phys. Lett. 65, 5313 (1994).

${ }^{18}$ J. S. Lash, R. M. Gilgenbach, and H. L. Spindler, Plasma Sources Sci. Technol. 4, 511 (1995).

${ }^{19}$ R. M. Gilgenbach, C. H. Ching, J. S. Lash, and R. A. Lindley, Phys. Plasmas 1, 1619 (1994).

${ }^{20}$ R. M. Gilgenbach and P. L. G. Ventzek, Appl. Phys. Lett. 58, 1597 (1991). 